\title{
Status of some fishery resources in a tropical mangrove estuary of Sarawak, Malaysia
}

\begin{abstract}
This study was carried out to assess the fishery resources of the Sibuti River estuary, Sarawak, Malaysia. Data were collected from the study area for a period of one year in different seasons. The estuary is relatively species-rich and a total of 4675 individuals of 32 families from 60 species of fish (55), crab (four) and shrimp (one) were collected. Coilia dussumieri was the dominant species $(22.63 \%)$ followed by Nemapteryx caelata $(11.85 \%)$, Otolithes ruber $(7.85 \%)$ and Ilisha elongata (5.80\%). Marked seasonal variations were found among most of the hydrobiological factors; however, seasonal variations were not significant for the diversity indices such as Shannonï Wiener, Margalef and Evenness. The number of fish taxa caught in different mesh size gill nets was 1 inch (42 species) $>2$ inch (36 species) $>4$ inch ( 25 species), suggesting that smaller mesh nets are more suitable for assessing the diversity of fishery resources. SIMPER analysis showed that Coilia dussumieri was the most abundant species in the dry $(10.3 \%)$ and intermediate $(8.1 \%)$ seasons, whereas N. caelata was most abundant in the wet season (7.1\%). Significant differences (ANOSIM and nMDS) were observed in the species community structure between dryï intermediate and dryï wet seasons; however, species compositions were not significantly different between intermediate and wet seasons. Canonical correspondence analysis (CCA) showed that most of the species assemblages were positively correlated with turbidity and chlorophyll a, followed by phosphate, nitrate and zooplankton density. The findings suggest that the Sibuti mangrove estuary is productive in terms of diversified fishery resources, which are influenced by the hydrobiological factors.
\end{abstract}

Keyword: Fishery resources; Hydrobiological factors; Mangrove estuary; Sarawak; Seasons 